\title{
Sensory Ecology of Predator-Induced Phenotypic Plasticity
}

\author{
Linda C. Weiss* \\ Department of Animal Ecology, Evolution and Biodiversity, Ruhr University Bochum, Bochum, Germany
}

Ecological communities are organized in trophic levels that share manifold interactions forming complex food webs. Infochemicals can further modify these interactions, e.g., by inducing defenses in prey. The micro-crustacean Daphnia is able to respond to predator-specific chemical cues indicating an increased predation risk. Daphnia shows plastic responses by adapting its morphology, behavior, and physiology, increasing organism, and population fitness. This stabilizes community structures. This review will describe the progress that has been made in understanding the high degree of plasticity observed in the model crustacean Daphnia. I summarize current knowledge on the processes of predator detection, ranging from the nature of biologically active chemical cues to the underlying neurophysiological mechanisms. With this, I aim to provide a comprehensive overview on the molecular mechanisms of ad hoc environmental phenotypic adaptation. In times of climate change and pollution understanding information transfer in aquatic systems is valuable as it will allow us to predict whether and how community structures are being affected.

OPEN ACCESS

Edited by:

Evan Preisser,

University of Rhode Island,

United States

Reviewed by:

Brian Wisenden,

Minnesota State University Moorhead,

United States

Ian C. G. Weaver,

Dalhousie University, Canada

*Correspondence:

Linda C. Weiss

linda.weiss@rub.de

Received: 29 September 2018 Accepted: 13 December 2018

Published: 18 January 2019

Citation:

Weiss LC (2019) Sensory Ecology of

Predator-Induced Phenotypic

Plasticity.

Front. Behav. Neurosci. 12:330.

doi: 10.3389/fnbeh.2018.00330
Keywords: phenotypic plasticity, daphnia, protocerebrum, deutocerebrum, chemoreceptors, neckteeth, inducible defenses

\section{INTRODUCTION-SENSORY SYSTEMS}

Organisms have evolved the capacity to respond to changes in the environment by phenotypic adaptation. Fluctuations in the biotic environment are dominated by the ever-changing presence and absence of con- and heterospecific organisms, prey, and predators. Therefore, detecting mates, prey or predators, and responding appropriately is critical for organisms' survival. Species have evolved dedicated sensory systems that are optimized to their particular ecology. Chemical perception is of central importance, alongside vision, mechanoreception, and electrical senses (Wisenden, 2000; Ferrari et al., 2010). Chemical cues are of particular relevance in aquatic environments as they can be identified regardless of turbidity and are reliable in space and time. Many prey organisms are able to detect the presence of predators even against a background of high chemical diversity. This allows the prey to respond to predator presence with plasticity of their phenotype and increase survival chances. Yet, for any kind of plasticity to be adaptive in the context of an increased risk of predation, the correct interpretation of the environmental challenge is pivotal, as a mal-adapted phenotype could in fact increase its predation risk. Understanding the sensory mechanisms and neuronal pathways underlying predator perception is also critical in the light of anthropogenic disturbances, which often interfere with neuronal signaling cascades.

This review focuses on the neuronal mechanisms underlying predator-induced morphological plasticity. Other defensive strategies like behavioral and life history adaptations, have so far received less attention. I will introduce the concepts of phenotypic plasticity and inducible defenses and explain their ecological relevance. 
I summarize the general insights that underlie chemical predator perception, neuronal wiring, neurophysiology, and neuronal plasticity.

This review centralizes on the perception and neuronal processing of kairomones. In the classical and broad sense kairomones are defined as interspecific chemical cues perceived by a benefiting prey to reduce the negative impact of a natural enemy (Ruther et al., 2002). As there are already numerous, valuable, and detailed reviews on the perception of chemical alarm pheromones (Sorensen and Stacey, 2004; Døving and Lastein, 2009; Dew et al., 2014; Ahuja et al., 2015; Lastein et al., 2015; Wisenden, 2015), these and the perceptive mechanisms will not be reviewed here.

I detail current knowledge of predator detection and neuronal signaling of predator-induced morphological plasticity in the freshwater crustacean Daphnia. This zooplankter is an important component of freshwater food webs, showing a strong plasticity against a range of predators. Several Daphnia genomes have now been sequenced (Colbourne et al., 2011; Ye et al., 2017, www.fleabase.org) and accordingly molecular biology applications (e.g., in situ hybdridization, RNAi, etc.) are becoming available (Kato et al., 2012; Nakanishi et al., 2014; Naitou et al., 2015; Nong et al., 2017). Many studies have investigated the changes in gene expression levels that affect morphological defense expression in Daphnia pulex (Schwarzenberger et al., 2009; Spanier et al., 2010; Miyakawa et al., 2015; Rozenberg et al., 2015, 2016; Hales et al., 2017), while only a few have looked at the (neuro-) physiological changes (Hanazato, 1991; Barry, 1999, 2002; Weiss et al., 2012a; Miyakawa et al., 2015).

\section{PHENOTYPIC PLASTICITY}

Genotypes equipped with adaptive strategies to increase individuals' fitness can help organisms to conquer environments with fluctuating conditions. From an ecological and evolutionary perspective, phenotypic plasticity is a powerful, and widespread means of organismal adaptation. Phenotypically plastic organisms may respond to environmental extremes, and Bradshaw was one of the first to recognize the importance of genetic variation of plasticity in an evolutionary context (Bradshaw, 1965). She postulated that plasticity should be understood as a trait that underlies evolutionary trajectories, such as selection. Moreover, phenotypic plasticity can be discussed as a means of evolution affecting biodiversity by enabling better niche use or the exploitation of several niches. Evolution of adaptive phenotypic plasticity has led to the success of organisms in novel habitats, and potentially contributes to genetic differentiation and speciation (Miner et al., 2005; West-Eberhard, 2005; Theißen and Melzer, 2016). An expanding body of work examines how plasticity can affect all levels of ecological organization through effects on demographic parameters, but also through direct and indirect species interactions, such as competition, predation, and coexistence (reviewed in Miner et al., 2005). For example, there are recent arguments that predator-induced plasticity makes evolutionary change possible and that evolution may be preceded by genetic assimilation (Reger et al., 2018).

Despite the growing body of work, the question of how plasticity is realized remains and the underlying molecular mechanisms are often unexplored. To elucidate these pathways, it is important to first distinguish whether the phenotypic adaptations are induced by biotic or abiotic environmental cues. The abiotic environment can affect the phenotype by physical laws (Kelly et al., 2012). So, for example, temperature can cause phenotypic changes through enzyme kinetics and diffusion rates (Kelly et al., 2012). Similarly, low nutrient availability can impact growth and morphology. Cold acclimation is known to result in metabolic responses involving increases in mitochondrial amount and capacity (Healy et al., 2017). Other examples of abiotic induction of plasticity are photoperiod-induced life history shifts in aphids (Simon et al., 2011) and timing of metamorphosis in amphibians (Wright et al., 1988).

Biotic environmental challenges originate from con- and heterospecifics and are in general signaled through chemical cues: predators release semiochemicals (kairomones), which indicate predation risk and conspecifics may release density cues, which modify and fine tune the response (Tollrian et al., 2015). The phenotypic change is realized through a complex interaction between these environmental chemical cues and organismal sensors. For example, prey species sense the chemical cues released by their predators. The active sequence of events from cue release $\rightarrow$ cue perception $\rightarrow$ signal transmission $\rightarrow$ endocrine signaling $\rightarrow$ phenotype adaptation is mostly elusive (Beldade et al., 2011; Morris and Rogers, 2014). One particular form of phenotypic plasticity are inducible defenses, where the phenotype is adapted to an increased predation risk.

\section{INDUCIBLE DEFENSES}

Predation is a major factor driving adaptation and predatorinduced defenses are an intriguing form of phenotypic plasticity that can decrease the likelihood of predator encounter or detection, and reduce the effectiveness of predator attacks. Ecologically, inducible defenses have been discussed to be of high importance as they dampen predator-prey oscillations, thereby stabilizing population dynamics (Verschoor et al., 2004). Many different defensive strategies expressed against an increased predation risk have been described (reviewed in Tollrian and Harvell, 1999). Defenses may occur in the form of behavioral or morphological adaptations or shifts of life history parameters, and many taxa show a variety of different anti-predatory adaptations (reviewed in Weiss et al., 2018).

For precise development of the appropriate defense, prey organisms must be able to accurately distinguish between predators; the expression of a defense that is not effective against the predator may pose a disadvantage and thereby reduce organism fitness (reviewed in Weiss and Tollrian, 2018). In addition, prey organisms must also be able to respond to multiple predators simultaneously as in most ecosystems predation is not limited to a single predator. All this is further complicated, as 
the expression of inducible defenses is not simply adapted to the predator but also to the predation risk (Tollrian et al., 2015; Crane and Ferrari, 2017). It was shown that, with growing conspecific numbers conspecific chemical cues indicate that the predation risk decreases, upon which defense expression is reduced (Peacor, 2003; Tollrian et al., 2015).

The fact that organisms are able to distinguish between predators, con- and heterospecifics and perform predation risk assessment in combination with a fine-tuned defense expression, shows that dedicated sensory systems must have evolved, enabling correct interpretation of the environment. The freshwater crustacean Daphnia has been especially well-studied for its capacity to express a diversity of inducible defenses.

\section{INDUCIBLE DEFENSES IN DAPHNIA}

Inducible defenses in Daphnia are manifold. Some Daphnia species show behavioral adaptions to fish predation (Figure 1). They perform fish-induced diel vertical migration, seeking refuge in the deeper water strata during the day, in order to escape visual predators (Ringelberg, 2010). Intriguingly, this defensive strategy is induced by two co-occurring cues: the predator and light conditions. Also, reduced swimming speeds have been reported to occur countering predation by the tactile predator the phantom midge larvae Chaoborus (Dodson et al., 1997). Shifts of life history parameters, are similarly expressed against fish predation (Brett, 1992; Hanazato et al., 2001, Figure 2; Boersma et al., 2009). Here somatic growth is traded with reproduction and the presence of fish induces early maturation at a smaller size and the production of more and smaller offspring in subsequent generations (Brett, 1992; Tollrian, 1995; Carvajal-Salamanca et al., 2008; Boersma et al., 2009).

Morphological defenses in Daphnia have been in the focus of ecological research for decades (Krueger and Dodson, 1981; Tollrian, 1993; Stollewerk, 2010; Tollrian and Leese, 2010; Weiss et al., 2012b); including helmet development in $D$. cucullata (Tollrian, 1990, Figure 3A) and neckteeth expression in D. pulex against Chaoborus spec. predation (Krueger and Dodson, 1981; Tollrian, 1993; Weiss et al., 2016, Figure 3B), crest development in $D$. longicephala against the heteropteran backswimmer Notonecta spec. (Grant and Bayly, 1981; Weiss et al., 2015, Figure 3C), head- and tail-spine development in D. lumholtzi against fish predation (Tollrian, 1994, Figure 3D) and crowns of thorns in D. atkinsoni against the tadpole shrimp Triops spec. (Petrusek et al., 2009).

\section{PREDATOR-SPECIFIC CHEMICAL CUES-IDENTIFICATION OF FRIENDS AND FOES}

Sensory information often plays a pivotal role in shaping species interactions (Hay, 2009). Species acquire information about their biotic and abiotic environment by detecting specific chemical cues (Atema et al., 1988). Organisms with poor vision and those in turbid environments are particular beneficiaries of chemical cues. Furthermore, chemical cues can be transmitted over long temporal, and spatial scales (Wisenden, 2000). A network of chemical cues is speculated to significantly complicate our current knowledge of trophic interactions (Burks and Lodge, 2002; Pohnert et al., 2007). It is therefore obligatory to not only describe trophic interactions per se but also identify the modifying agents. The different type of cues are distinguished based on their origin; so that the sources need to be determined prior to correct categorization into either alarm cues or predator specific cues (Hazlett, 2011; Wisenden, 2015). Sometimes, this even requires the chemical identification of the compound(s). While alarm cues are chemicals of conspecific prey, and released upon mechanical damage of the same, predator specific cues are generally unintentionally released by the predator. Predator cues can also be but do not have to be associated to foraging activities (Mitchell et al., 2017). While there are numerous reviews on alarm cues (Hazlett, 2011) some with the special focus on fish (Døving and Lastein, 2009; Lastein et al., 2015; Wisenden, 2015), predator specific cues are less well-reviewed and will therefore be the focus here.

Interspecific chemical cues released by predators induce the development of defensive features in prey organisms (Tollrian and Harvell, 1999; Weiss et al., 2012b). These, so-called, kairomones are released by a sender serve as an advantage for a receiver, as in this context they indicate an increased predation risk. Kairomones decrease the efficiency of the predator (Jeschke et al., 2002) thereby affecting the dynamics of entire food webs (Kats and Dill, 1998; Dicke and Grostal, 2001; Verschoor et al., 2004; Vos et al., 2006).

When these substances are associated with foraging activities, the value of this cue as a signaling agent increases significantly for the prey organisms and evolution of sensitivity to such cues should be favored. Unfortunately, many of the infochemicals's structure and/or composition remain elusive. Kairomones have disparate chemistry, for example they can be proteins that signal the development of inducible defenses in ciliates (Kusch and Heckmann, 1992), which develop lateral wings in the presence of the predatory ciliate Lembadion. Alternatively, aliphatic sulfates released by Daphnia inducing defensive coenobia in algae (Yasumoto et al., 2005), and composites like the recently described copepodamides induce the production of the paralytic shell fish toxin in the dinoflagellate Alexandrinum minutum (Selander et al., 2015). Trigonelline and homarine were shown to induce fear in mud crabs (Poulin et al., 2018). In rodents, fear responses are induced by volatile molecules such as TMT, 2-PEA, and 2-PT, which result from meat digestion in the predator (Pereira and Moita, 2016).

These signals appear to be enormously diverse in chemical and temporal structure, and the ability to identify and quantitate them, especially from the aquatic environment, has been a major challenge in chemical ecology. The identification of such signaling agents is however a pivotal component in our understanding of predator perception. Of course, chemoreceptors play a critical role, where the identification and deorphanization of an explicit chemoreceptor requires knowledge of the ligand. 

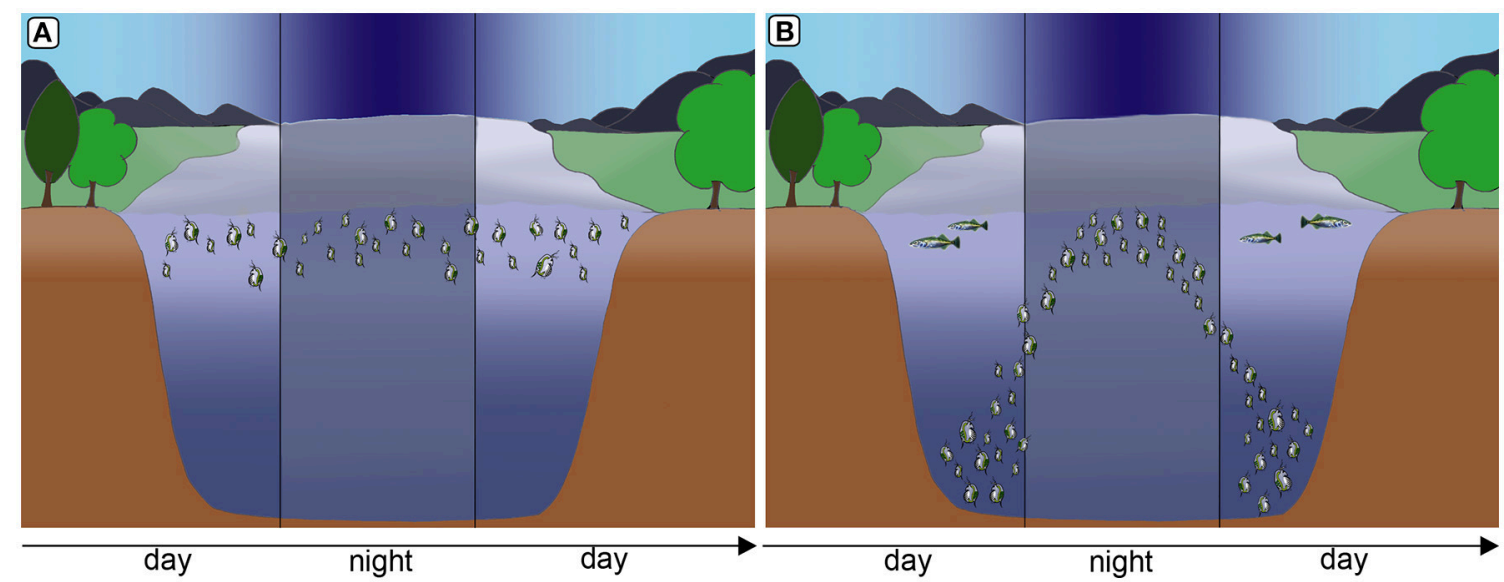

FIGURE 1 | Diel vertical migration as a form of behavioral defense in Daphnia to counter fish predation. In the absence of fish predation Daphnia remain in warm, nutritious water strata (A). Under predation, Daphnia migrate to deeper water strata, seeking refuge from visual predators. However, during the night they migrate to nutrient rich and warmer strata for feeding (B). Images by Weiss.

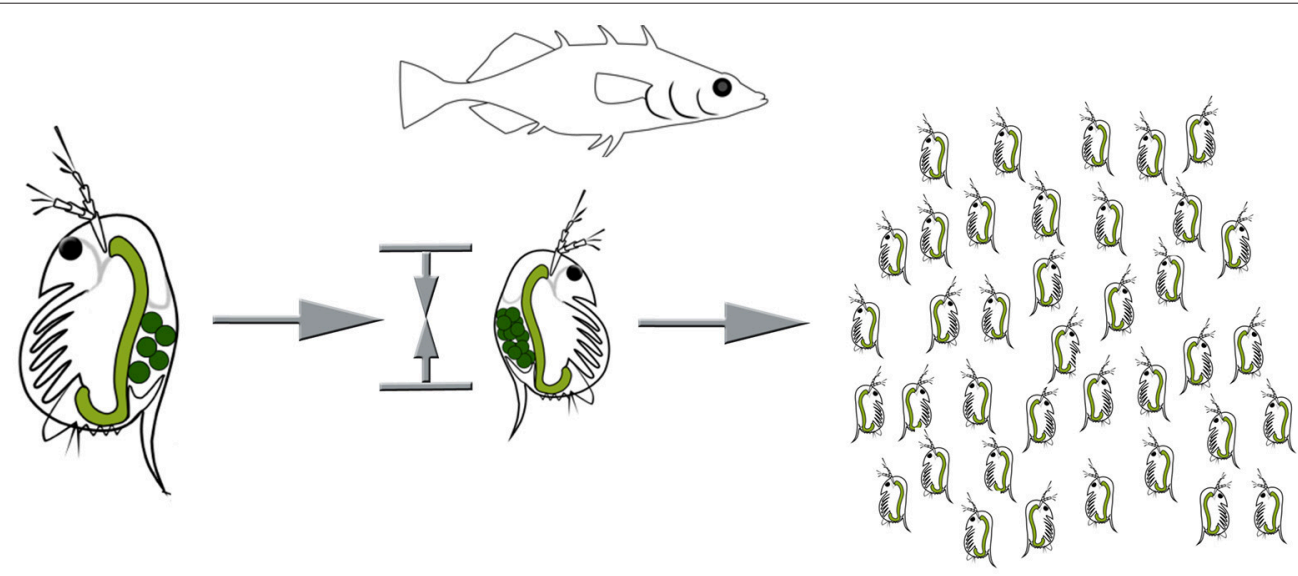

FIGURE 2 | Life history adaptations under fish predation. Resources are shifted from somatic growth to reproduction, resulting in earlier sexual maturity at a smaller size, and an increased number of smaller offspring. Images by Weiss.

\section{THE CHAOBORUS KAIROMONE}

Fourth instar phantom midge larvae of the genus Chaoborus (Diptera) prey upon juvenile $D$. Pulex. The larvae grasp the daphniid prey with their feeding basket composed of head appendages. The prey is captured and consumed by alternating movements of the mandibles. All digestible parts are consumed, and the indigestible components are egested. The kairomone is released during the egestion process. It comprises a family of compounds consisting of long-chained ( $\geq$ C14) fatty acids coupled to the $\mathrm{N}$-terminus of an L-glutamine residue. Lipidated -L-glutamine conjugates released by feeding Chaoborus larvae trigger defensive neckteeth formation in juvenile Daphnia (Weiss et al., 2018).

These molecules carry characteristics of suitable aquatic infochemicals: they are water-soluble and thus pass from the emitting organism (i.e., predator) to the receiving organism (e.g., prey). Additionally, because of their origin from active digestion they are good indicators of predation risk.
Regarding the origin of the kairomone, it is anticipated that the larvae take up fatty acids from their diet (in this case the Daphnia, yet Chaoborus also consumes e.g., ciliates and this rearing medium also induces defensive neckteeth, Tollrian personal communication) and use them for glutamine assimilation in the mid-gut as seen in many caterpillars or other dipteran species like Drosophila (Mori and Yoshinaga, 2011; Yoshinaga, 2016). Glutamine seems to function as a nitrogen storage as it is mandatory for many biosynthetic pathways. This also explains why co-evolution leading to suppression of chemical release is hampered. Unsurprisingly, substances whose production cannot be avoided are exploited as reliable interspecific information cues by the different prey species. The active components of the Chaoborus kairomone are only produced during active feeding, however the type of diet is irrelevant (Tollrian, personal communication). For categorization purposes, this means that the Chaoborus kairomone is not a dietary alarm cue, but an activity dependent compound produced by the predator during digestion. It is 
A
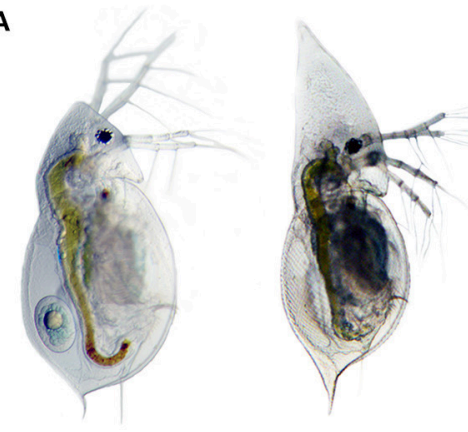

C

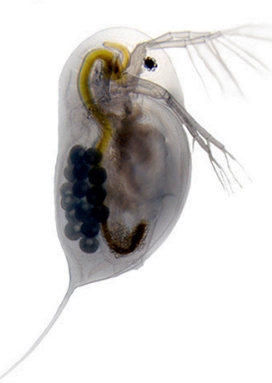

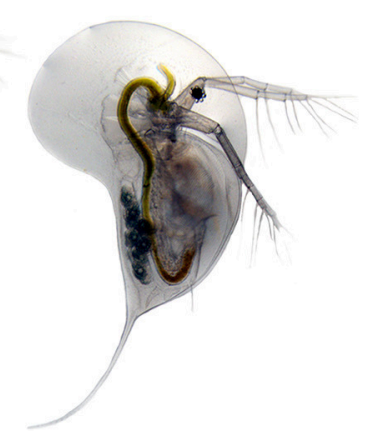

B

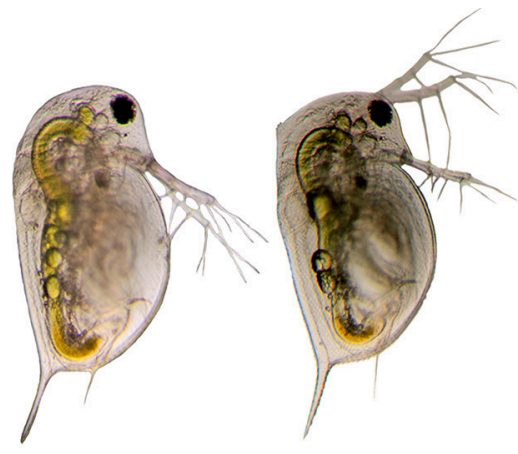

D
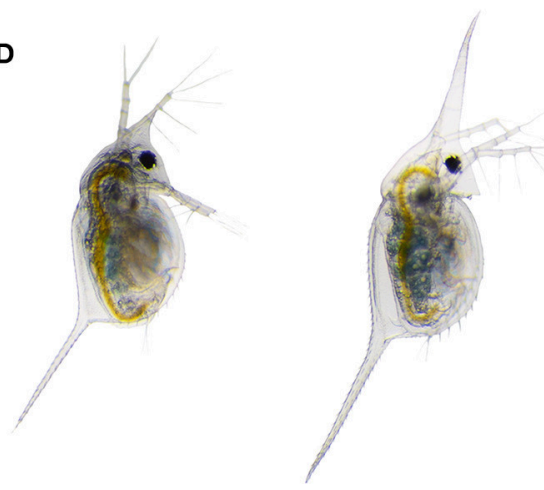

FIGURE 3 | Inducible morphological defenses are manifold in the genus Daphnia. The listed examples show helmet expression in D. cucullata (A); crest expression in D. longicephala (C); head- and tail-spine formation D. lumholtzi (D), and neckteeth expression in D. pulex (B). Undefended morphotypes are displayed on the left side, and the defended morphotype on the right side. Images by Becker \& Weiss.

beneficial for the predator only in the context of metabolism. A benefit in the context of information transfer is only advantageous for the receiver, i.e., the prey.

Having the information of the inducing agent is critical for the identification of respective chemoreceptors and the signaling pathways used to detect such cues within environmental noise.

\section{CHEMORECEPTORS}

By 1991 Buck and Axel had identified a set of ca. 1,000 olfactory receptors (ORs) in rats (Buck, 1996). These belong to a class of rhodopsin-like G-protein coupled receptors (GPCRs) and have been identified in all vertebrates. No homologs of these receptors have been detected in any protostome. In insects, a distinct group of ORs and gustatory receptors (GRs) have been described that are not homologs to the vertebrate ORs (Vosshall et al., 1999). They represent an individual gene family, with the GRs being the ancestral type. These are ionotropic receptors (ligandgated ion channels), similar to traditional ionotropic glutamate receptors such as kainite, $\mathrm{N}$-methyl-D-aspartate (NMDA), and AMPA receptors. Compared with vertebrate ORs, insect ORs show an inverted membrane topology with extracellular carboxyl and intracellular amino terminals (Galizia and Sachse, 2010). Insect ORs function as heteromultimers composed of at least one ligand-specific OR and the co-receptor Orco (Vosshall et al., 1999; Galizia and Sachse, 2010; Wicher, 2018). Neither Orco nor ORs are present in the genome of the crustacean D. pulex, indicating that ORs are insect specific. However, GRs were found in Crustacea, just as in insects (Peñalva-Arana et al., 2009).

Another example of chemoreceptor proteins is a subset of ionotropic receptors (IRs) found in all protostome clades, known as the IRs. These probably evolved from the non-NMDA ionotropic glutamate receptors in ancient protostomes (Croset et al., 2010).

For a comprehensive review of the different chemoreceptor proteins and their evolution please refer to (Vosshall et al., 1999; Derby et al., 2016; Brand et al., 2018).

Our understanding of how predator kairomones are perceived and processed is very limited and dedicated chemoreceptors have predominantly been identified in mice (Isogai et al., 2011). In this study, con- and heterospecific chemical cues stimulated neurons in the vomeronasal organ (VNO) were screened for chemoreceptor expression (Isogai et al., 2011). It was thus possible to detect the activation of neurons with specific receptors during chemical cue exposure. The authors found that within the 250 receptors that are expressed in the $\mathrm{VNO}$ of mice, 71 receptors in total exclusively respond to heterospecific cues, only 11 of these receptors also responded to conspecific cues (Isogai et al., 2011). Intriguingly, some receptors were exclusively responsive to different types of predators so that two receptors responded to snake cues, while others responded to owl cues. Each predator species tested activated a distinct subset of receptors, pointing to the capacity of mice to be able to distinguish between predators (Isogai et al., 2011). 
In general, chemical cues bind to chemoreceptors that are located on some kind of chemoreceptive organ innervated by olfactory receptor neurons (ORNs).

Olfactory wiring is achieved as one ORN expresses one functional receptor type, and all ORNs expressing the same receptor type coalesce in one glomerulus of the odor information processing region e.g., the olfactory lobes in arthropods (Strausfeld and Reisenman, 2009), or the olfactory bulb in mammals (Nagayama et al., 2014).

\section{CHEMORECEPTORS IN DAPHNIA}

Compared with other taxa (like insects and mammals) not much is known about chemoreceptors in Daphnia. There is a known repertoire of 58 chemoreceptors that cluster in 3 distinctive superfamilies and share sequence homology with insect gustatory receptors (Grs). No genes encoding proteins similar to the insect odorant receptors (Ors) were found, which might indicate a quite recent expansion of this gene lineage concomitant with the evolution of hexapods (Peñalva-Arana et al., 2009). This is further supported by the observation that, as yet, Ors are also absent in other crustacean genomes. Yet, it is highly questionable that Daphnia relies on these 58 Grs only. Recently, it was reported that crustacean olfactory receptors are orthologs of insect olfactory IRs and the Daphnia genome holds an abundant number of IRs (Croset et al., 2010). In fact, it was shown later in lobsters that two IR subunit genes PargIR25a and PargIR93a are expressed in most or all spiny lobster ORNs, as confirmed by in situ hybridization (Corey et al., 2013). Other encoded IR subunits are expressed only sparsely, suggesting an ORN-specific expression pattern. This suggests that, as in insects, the odorant specificity of individual lobster ORNs is determined by a specific set of expressed subunits and that these subunits are composed of IR25 $a$ and/or IR93a co-receptors (Croset et al., 2010; Corey et al., 2013).

Thus, it is likely that IRs play a general role in initiating chemosensory signaling in crustaceans and also in Daphnia. Yet, limited attempts have been undertaken for heterologous expression and deorphanization of the chemoreceptors that have been identified by sequence homology with other arthropods. It is also likely that there are additional classes of chemoreceptors yet to be discovered (Derby et al., 2016; Harzsch and Krieger, 2018).

For a precise description of how environmental chemical cues are decrypted, it is pivotal to deorphanize receptors specific for kairomones but also disentangle the underlying neuronal structures involved in kairomone perception such as nervous fibers and the computational steps in higher brain areas.

\section{NEURONAL WIRING OF OLFACTORY RECEPTOR NEURONS}

Neural circuits are both anatomical and functional entities and the involved neurons never function in isolation. Such neuronal circuits process specific kinds of information and their identification is crucial for the understanding of how sensory information is encoded. There is a general concept of odorant coding found in vertebrates and invertebrates. Odorants are first detected by chemoreceptors located on ORNs. The axons of the neurons then organize centrally into glomeruli organized by olfactory receptor type (Vosshall et al., 1999; Derby et al., 2016; Harzsch and Krieger, 2018). A glomerulus is a roundish substructure that contains most synapses within the antennal lobe or olfactory bulb (depending on taxon). In vertebrates and invertebrates alike, projection neurons (PNs) relay olfactory inputs to higher-order brain areas like the mushroom bodies and the lateral horns (in insects). These brain areas permit associative learning or mediate innate behaviors (reviewed in Galizia and Rössler, 2010).

While the projection neurons are uni- and multiglomerular and suspected to be of cholinergic pharmacology (Galizia and Rössler, 2010), there are also local neurons (LNs) that interconnect the glomeruli and are of the amacrine type (Homberg et al., 1989). They are diverse in morphology and controlled by inhibitory neurotransmitters like GABA or excitatory neurotransmitters like acetylcholine. For further detail please see Galizia and Rössler (2010); Galizia and Sachse (2010); Derby et al. (2016); Harzsch and Krieger (2018).

\section{NEURONAL AND CELLULAR WIRING IN DAPHNIA}

In order to understand the cellular mechanisms of plasticity, an overview of the overall nervous system and the functioning of the individual components is necessary. Even if the neuroanatomy of the Daphnia nervous system appears comparatively simple, it is known to be able to discriminate a vast array of intra- and interspecific signals. The Daphnia brain is of classical arthropod organization and consists of three regions, the protocerebrum, the deutocerebrum, and the tritocerebrum (syncerebrum) as described in other branchiopod crustacean species (Harzsch and Glötzner, 2002; Kirsch and Richter, 2007; Fritsch and Richter, 2010; Kress et al., 2016). In the protocerebrum, the optical neuropils are connected via the optical tracts with its remaining scaffold (Weiss et al., 2012c). The deutocerebrum receives nerve fibers from the antennule (Weiss et al., 2012c, Figure 4A). Nerves originating from the tritocerebral ganglia enter the antenna, the labrum, and the alimentary tract (Weiss et al., 2012c). The tritocerebrum is thus also involved in functions of the stomatogastric nervous system (Heribert, 1915; Bullock, 1965; Weiss et al., 2012c). The protocerebrum is the anterior-most neuropil and comprises the largest portion of the brain (Figures 4B-D). The deutocerebrum is proximal to the protocerebral neuropil. The deutocerebral neuropil is less distinctive than the protocerebrum and consists of a pair of undifferentiated neuropils (Hallberg et al., 1992; Harzsch, 2006). The question now is, how are such adaptive processes encoded on the neuronal level. The receptors for the detection of predator cues were shown to be located on the first antennae (Weiss et al., 2015, Figure 4A). From here neurites extend to the deutocerebrum of the brain (Weiss et al., 2012c, Figures 4A,D). Yet, olfactory glomeruli in the deutocerebrum have not been detected Hallberg et al., 1992; Weiss et al., 2012c and the precise wiring underlying predator detection in Daphnia is unknown. 
Likewise, the chemical and functional description of individual brain cells and specialized brain centers is yet understudied. For example, there is a group of serotonergic cells located in the protocerebrum that probably control phototactic behaviors (Rivetti et al., 2018, Figure 4B) and may therefore also be involved in predator-induced diel vertical migration patterns, which are triggered by changes in light intensity (Ringelberg, 2010).

On the cellular level outside the nervous system, a group of large polyploid cells located in close association with the morphological defense structure in various daphniid subgenera was suggested to be involved in the development of defensive traits (Figure 4E). These cells were speculated to serve as central control stations secreting proliferation agents (Beaton and Hebert, 1997) like dopamine inducing the mitotic activity in the vicinity of these cells (Weiss et al., 2015). Nonetheless, it remains only speculative how these cells are controlled and how they determine the development of phenotypically plastic morphological defenses.

\section{NEUROPHYSIOLOGY OF PREDATOR-INDUCED DEFENSES IN DAPHNIA}

Neurophysiological stimulation studies have shown that the cascade underlying predator perception and defense expression, comprises multiple signaling components, including the involvement of cholinergic, glutaminergic and GABAergic signaling (Weiss et al., 2012a; Miyakawa et al., 2015). In general, acetylcholine in the brain alters neuronal excitability, influences synaptic transmission, induces synaptic plasticity, and coordinates firing of groups of neurons (Picciotto et al., 2012). As a result, it changes the state of neuronal networks throughout the brain and modifies their response to internal and external inputs, which is the classical role of a neuromodulator (Picciotto et al., 2012). Glutamate is a dominant neurotransmitter in nervous systems and activates neurons (Meldrum, 2000). Neuronal receptors for glutamate are divided into two groups: the metabotropic glutamate receptors, which are members of the G-protein coupled receptor family, and ionotropic glutamate receptors, which are members of the ligand-gated ion channel family. Ionotropic glutamate receptors are further divided into three groups whose names are derived from specific agonists: NMDA-type, $( \pm)$ - $\alpha$-amino-3-hydroxy-5-methyl-4-isoxazolepropionic acid (AMPA)-type and kainate-type (Meldrum, 2000). These subtypes are expressed mainly in central nervous systems and are involved in various biological processes, including memory and learning, in many animal species (Malenka and Nicoll, 1999). Genes coding for these receptors were identified using microarrays and their involvement in defense expression was further validated with a functional analysis using the receptors' antagonists (Miyakawa et al., 2015).

GABA is a major inhibitory neurotransmitter, reducing a nerve cell membrane potential and thereby decreasing its excitability (Wu and Sun, 2015). GABA is always functional in the nervous system, fine-tuning neuronal responses and controlling neuronal firing rates (Wu and Sun, 2015). In predator-exposed D. pulex, genes for G-protein coupled GABA receptors were differentially expressed (Miyakawa et al., 2015). Only the GABA receptor type is metabotropic and therefore G-protein coupled. While Barry (2002) antagonized the actions of GABA using picrotoxin, a non-competitive antagonist of the ionotropic $\mathrm{GABA}_{\mathrm{A}}$ receptor (Barry, 2002), neurophysiological stimulation with GABA did not validate direct involvement of GABergic signaling (Weiss et al., 2012a). Indirect GABAergic signaling is reasonable, but not observable with simple neurophysiological stimulation in bioassays. Rather this requires e.g., patch-clamp measurements of ion currents in culture cells, or optogenetic strategies applied in vivo (Spoida et al., 2014).

\section{NEURONAL PLASTICITY}

Ever since the pioneering work of Drs. Hubel and Wiesel more than 40 years ago, neurobiologists have appreciated that the environment plays an essential role in shaping neural connectivity. These observations are framed by the term neuronal plasticity, which is known as the ability of the brain to change throughout an individual's life. This includes changes in gray matter, constant removal and creation of synapses depending on the activity level, or dendritic outgrowth adjustment all according to neuronal activity levels. This kind of activity-dependent plasticity is a form of functional and structural neuroplasticity arising from cognition and experience. It is thus the basis for learning and the formation of memories. Also, neuronal plasticity is a result of changes in gene expression patterns triggered by dedicated signaling cascades activated by signaling molecules such as calcium, dopamine, and glutamate.

Within an ecological perspective it has been seen that both relative brain size and structure are statistically correlated with environmental parameters. These include spatial complexity of the natural and social environment, water depth, light environment, and predation (Samuk et al., 2018). For example, an analysis of 623 pairs of predator and prey species of fish found that on average, prey species tend to have larger brains than the species that prey upon them, perhaps suggesting a "cognitive arms race" (Samuk et al., 2018).

Other studies described how predator exposure can change brain morphology e.g., predator exposed nine-spined sticklebacks grow larger bulbi olfactorius (Gonda et al., 2011), but the opposite effect has also been observed where predator-exposed brains become shorter and narrower. The underlying cause of this change in morphology, however, was not investigated. It remains elusive, from where the structural change originates, so that an increase in brain size could indicate an increased number of nerve cells or an increased number of cellular connections.

\section{NEURONAL PLASTICITY IN DAPHNIA}

If and how the neuroanatomy of the brain changes during predator exposure requires investigation. So far, only the involvement of NMDA receptors, which only respond 

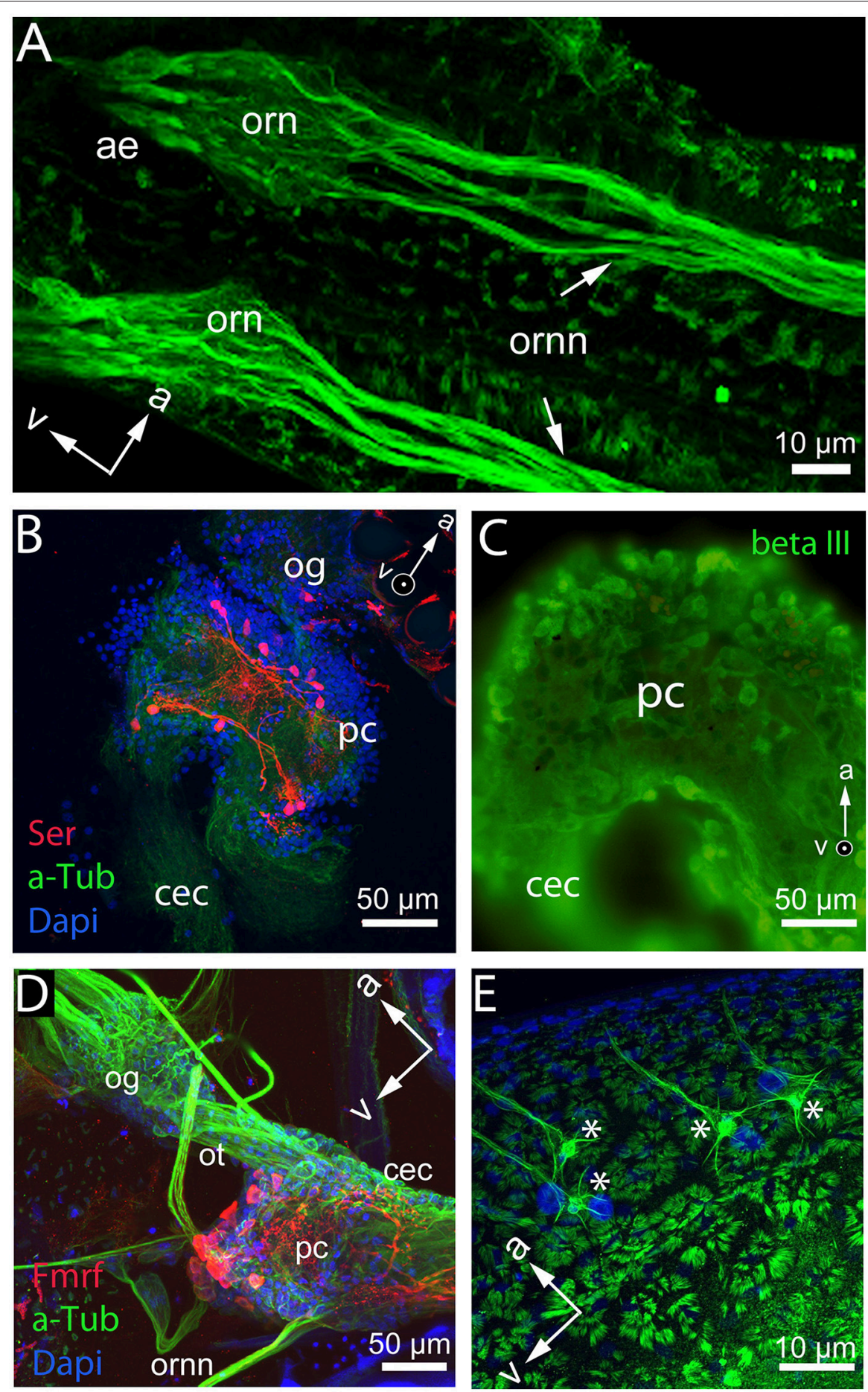

FIGURE 4 | Whole mount and brain mount preparation of the Daphnia nervous system displaying differential functional qualities of cells. (A) Base of the antennules and cuticular insertion of the aesthetascs (ae) with olfactory receptor neurons (orn) and olfactory receptor neuron neurites (ornn) extending from the first antennule to the deutocerebrum of the brain in D. longicephala. (B) Protocerebrum (pc) and optic ganglia (og) of D. magna show neurons stained with anti-serotonin antibody (red). Cytoskeleton is stained with anti-alpha tubulin (green) and nucleoli with dapi (blue). (C) Protocerebrum overview of the D. longicephala brain stained with an antibody detecting neuron-specific beta III tubulin. (D) Whole mount preparation of a D. longicephala head displaying the optic ganglia (og) connected via the optic tract (ot) with the protocerebrum (pc) extending into the circumesophageal connective that connects to the tritocerebrum (not shown). The olfactory receptor neurons connect to the central brain via the deutocerebrum. Nucleoli are stained in dapi displayed in blue, the cytoskeleton is stained with anti-alpha tubulin in green, and red displays cells with anti-Fmrfamide reactivity. (E) Polyploid cells (asterisks) lining the region of crest expression in D. longicephala stained with anti-alpha tubulin. Cells are characterized by a large nucleus stained with dapi (blue), lateral extensions, and one dominant extension innervating the epidermal cells of the crest. Orientation of the preparations is marked by arrows in the anterior (a) and ventral (v) directions. Images by loannidou \& Weiss. 
on over-activation due to the magnesium block and are known to be essentially involved in long-term potentiation in associative learning, points to a degree of synaptic neuronal plasticity.

While the perception of predators is performed by the above described actions of the nervous system, also epigenetic changes are anticipated to contribute to the modification of an organism's phenotype. Such changes can also be inherited to subsequent generations rendering these better adapted to environmental conditions.

\section{EPIGENETICS OF PREDATOR INDUCED DEFENSES}

Epigenetics study the emergence of different phenotypes that result from a single genotype (Bonasio, 2015). Up to date, only little attention has been paid to epigenetic modifications and how these may affect ecological interactions. Well-known changes are described by non-coding RNAs, histone modifications and cytosine methylation (Harris et al., 2012). Ultimately, all these mechanisms lead to changes in gene expression patterns, but do not change the DNA sequence itself. Epigenetic changes are of particular interest not only because they are affected by environmental conditions but also because of their heritability. This can either take place during meiosis or mitosis. During mitosis epigenetic changes are responsible for the maintenance of discrete transcriptional states and e.g., control cell identity over multiple rounds of cell division (Duncan et al., 2014; Bonasio, 2015). During meiosis epigenetic changes can be transferred to subsequent generations. So environmental changes may be epigenetically imprinted and passed on to offspring even after the initial stress has disappeared (Harris et al., 2012). The role of epigenetics in the context of defense systems and adaptive morphotypes is not yet fully exploited. Parthenogenetic organisms like Daphnia are discussed as valuable models for such endeavors (Harris et al., 2012; Robichaud et al., 2012), as they have the epigenetic repertoires (e.g., differential methylation Asselman et al., 2015 and histone modification Robichaud et al., 2012) as well as the explicit ability to express context dependent phenotypes within (Weiss and Tollrian, 2018) and across generations (Agrawal et al., 1999).

\section{OUTLOOK}

The ability of many organisms to adjust to the predation risk and to be able to distinguish between predators shows a distinct capacity to sense and interpret the environment. This is pivotal for an individual's fitness and ultimately for ecosystem stability.

In recent years, it has become increasingly clear, that many anthropogenic agents released into the environment affect the sensory systems of marine and freshwater species.

For example, many studies have demonstrated that elevated $\mathrm{pCO}_{2}$ levels in the oceans and in freshwater ecosystems affect organismal neurobiology (Nilsson et al., 2012; Hamilton et al., 2014; Weiss et al., 2018). In many cases this prevents the correct interpretation of the environment and can lead to inappropriate responses (Chivers et al., 2014; Weiss et al., 2018). This may render prey species more susceptible to predators, which can have cascading effects on the ecosystem level. Likewise, a number of laboratory studies suggest that anthropogenic pollutants can disrupt chemoreception, even at low, non-toxic concentrations, but there are few tests of whether real-world variation in water quality affects chemoreception (Troyer and Turner, 2015).

These observations demonstrate the necessity to further analyze chemical signaling cues together with the sensory mechanisms that mediate environmental adaptations. With next-generation sequencing strategies, genome mining for e.g., chemoreceptors is possible and also pivotal for any molecular investigations. The availability of novel genomeediting strategies (Crispr/Cas9, TALEN, RNAi) (Kato et al., 2012; Nakanishi et al., 2014; Naitou et al., 2015) in combination with optogenetic applications (Herlitze and Landmesser, 2007; Deisseroth, 2011) and electroantennograms (Simbeya et al., 2012) will allow us to further decipher the molecular mechanisms underlying predator-induced phenotypic plasticity.

\section{AUTHOR CONTRIBUTIONS}

The author confirms being the sole contributor of this work and has approved it for publication.

\section{FUNDING}

This review paper will be supported by the Ruhr University Bochum library funds for open access publication.

\section{ACKNOWLEDGMENTS}

I thank Annette Graeve and Ralph Tollrian for proof reading and Thomas White for correcting the English language.

methylation in Daphnia magna depends on genotype, environment, and their interaction. Environ. Toxicol. Chem. 34, 1056-1061. doi: 10.1002/ etc. 2887

Agrawal, A. A., Laforsch, C., and Tollrian, R. (1999). Transgenerational induction of defences in animals and plants. Nature 401, 60-63. doi: 10.1038/43425

Ahuja, G., Nia, S. B., Zapilko, V., Shiriagin, V., Kowatschew, D., Oka, Y., et al. (2015). Kappe neurons, a novel population of olfactory sensory neurons. Sci. Rep. 4:4037. doi: 10.1038/srep04037

Asselman, J., De Coninck, D. I. M., Vandegehuchte, M. B., Jansen, M., Decaestecker, E., De Meester, L., et al. (2015). Global cytosine
Atema, J., Fay, R. R., Popper, A. N., and Tavolga, W. N. (eds.). (1988). Sensory Biology of Aquatic Animals. New York, NY: Springer. doi: 10.1007/978-1-4612-3714-3

Barry, M. J. (1999). The effects of a pesticide on inducible phenotypic plasticity in Daphnia. Environ. Pollut. 104, 217-224. doi: 10.1016/S0269-7491(98)0 0188-2 
Barry, M. J. (2002). Progress toward understanding the neurophysiological basis of predator-induced morphology in Daphnia pulex. Physiol. Biochem. Zool. 75, 179-186. doi: 10.1086/339389

Beaton, M. J., and Hebert, P. D. N. (1997). The cellular basis of divergent head morphologies in Daphnia. Limnol. Ocean. 42, 346-356. doi: 10.4319/lo.1997.42.2.0346

Beldade, P., Mateus, A. R. A., and Keller, R. A. (2011). Evolution and molecular mechanisms of adaptive developmental plasticity. Mol. Ecol. 20, 1347-1363. doi: 10.1111/j.1365-294X.2011.05016.x

Boersma, M., Spaak, P., and Meester, L. (2009). Predator-mediated plasticity in morphology, life history, and behavior of daphnia. Am. Soc. Nat. 152, 237-248. doi: $10.1086 / 286164$

Bonasio, R. (2015). The expanding epigenetic landscape of non-model organisms. J. Exp. Biol. 218, 114-122. doi: 10.1242/jeb.110809

Bradshaw, A. D. (1965). Evolutionary significance of phenotypic plasticity in plants. Adv. Genet. 13, 115-155. doi: 10.1016/S0065-2660(08)60048-6

Brand, P., Robertson, H. M., Lin, W., Pothula, R., Klingeman, W. E., Jurat-Fuentes, J. L., et al. (2018). The origin of the odorant receptor gene family in insects. Elife 7:e38340. doi: 10.1101/259424

Brett, M. T. (1992). Chaoborus and fish mediated influences on Daphnia longispina population structure, dynamics and life history strategies. Oecologia 89, 69-77.

Buck, L. B. (1996). Information coding in the vertebrate olfactory system. Annu. Rev. Neurosci. 19, 517-544. doi: 10.1146/annurev.neuro.19.1.517

Bullock, T. H. (1965). Structure and Function in the Nervous Systems of Invertebrates. San Franscisco, CA: Wh Freeman.

Burks, R. L., and Lodge, D. M. (2002). Cued in: advances and opportunities in freshwater chemical ecology. J. Chem. Ecol. 28, 1901-1917. doi: $10.1023 / \mathrm{A}: 1020785525081$

Carvajal-Salamanca, J. L., Aránguiz-Acuña, A., Ramos-Jiliberto, R., and Zúñiga, L. R. (2008). Immediate and delayed life-history responses of Daphnia ambigua to conspecific cues. J. Plankton Res. 30, 1117-1122. doi: 10.1093/plankt/fbn071

Chivers, D. P., Mccormick, M. I., Nilsson, G. E., Munday, P. L., Watson, S. A., Meekan, M. G., et al. (2014). Impaired learning of predators and lower prey survival under elevated $\mathrm{CO}_{2}$ : a consequence of neurotransmitter interference. Glob. Chang. Biol. 20, 515-522. doi: 10.1111/gcb.12291

Colbourne, J. K., Pfrender, M. E., Gilbert, D., Thomas, W. K., Tucker, A., Oakley, T. H., et al. (2011). The ecoresponsive genome of Daphnia pulex. Science 331, 555-561. doi: 10.1126/science.1197761

Corey, E. A., Bobkov, Y., Ukhanov, K., and Ache, B. W. (2013). Ionotropic crustacean olfactory receptors. PLoS ONE 8:e60551. doi: 10.1371/journal.pone.0060551

Crane, A. L., and Ferrari, M. C. O. (2017). Evidence for risk extrapolation in decision making by tadpoles. Sci. Rep. 7:43255. doi: 10.1038/srep43255

Croset, V., Rytz, R., Cummins, S. F., Budd, A., Brawand, D., Kaessmann, H., et al. (2010). Ancient protostome origin of chemosensory ionotropic glutamate receptors and the evolution of insect taste and olfaction. PLoS Genet. 6:e1001064. doi: 10.1371/journal.pgen.1001064

Deisseroth, K. (2011). Optogenetics. Nat. Methods 8, 26-29. doi: 10.1038/nmeth.f.324

Derby, C. D., Kozma, M. T., Senatore, A., and Schmidt, M. (2016). Molecular mechanisms of reception and perireception in crustacean chemoreception: a comparative review. Chem. Senses 41, 381-398. doi: 10.1093/chemse/bjw057

Dew, W. A., Azizishirazi, A., and Pyle, G. G. (2014). Contaminant-specific targeting of olfactory sensory neuron classes: connecting neuron class impairment with behavioural deficits. Chemosphere 112, 519-525. doi: 10.1016/.j.chemosphere.2014.02.047

Dicke, M., and Grostal, P. (2001). Chemical detection of natural enemies by arthropods: an ecological perspective. Ann. Rev. 32, 1-23. doi: 10.1146/annurev.ecolsys.32.081501.113951

Dodson, S. I., Tollrian, R., and Lampert, W. (1997). Daphnia swimming behaviour during vertical migration. J. Plankton Res. 19, 969-978. doi: 10.1093/plankt/19.8.969

Døving, K. B., and Lastein, S. (2009). The alarm reaction in fishes - odorants, modulations of responses, neural pathways. Ann. N. Y. Acad. Sci. 1170, 413-423. doi: 10.1111/j.1749-6632.2009.04111.x

Duncan, E. J., Gluckman, P. D., and Dearden, P. K. (2014). Epigenetics, plasticity, and evolution: how do we link epigenetic change to phenotype? J. Exp. Zool. Part B Mol. Dev. Evol. 322, 208-220. doi: 10.1002/jez.b.22571
Ferrari, M. C. O., Wisenden, B. D., and Chivers, D. P. (2010). Chemical ecology of predator-prey interactions in aquatic ecosystems: a review and prospectus. Can. J. Zool. 88, 698-724. doi: 10.1139/Z10-029

Fritsch, M., and Richter, S. (2010). The formation of the nervous system during larval development in Triops cancriformis (Bosc) (crustacea, Branchiopoda): an immunohistochemical survey. J. Morphol. 271, 1457-14581. doi: 10.1002/jmor.10892

Galizia, C. G., and Rössler, W. (2010). Parallel olfactory systems in insects: anatomy and function. Аnnu. Rev. Entomol. 55, 399-420. doi: 10.1146/annurev-ento-112408-085442

Galizia, C. G., and Sachse, S. (2010). Odor Coding in Insects, ed A. Menini. Boca Raton, FL: CRC Press/Taylor \& Francis.

Gonda, A., Välimäki, K., Herczeg, G., and Merilä, J. (2011). Brain development and predation: plastic responses depend on evolutionary history. Biol. Lett. 8, 249-252. doi: 10.1098/rsbl.2011.0837

Grant, J. W. G., and Bayly, I. A. E. (1981). Predator induction of crests in morphs of the Daphnia carinata king complex. Limnol. Oceanogr. 26, 201-218. doi: 10.4319/lo.1981.26.2.0201

Hales, N. R., Schield, D. R., Andrew, A. L., Card, D. C., Walsh, M. R., and Castoe, T. A. (2017). Contrasting gene expression programs correspond with predatorinduced phenotypic plasticity within and across generations in Daphnia. Mol. Ecol. 26, 5003-5015. doi: 10.1111/mec.14213

Hallberg, E., Johansson, K. U. I., and Elofsson, R. (1992). The aesthetasc concept : structural variations of putative olfactory receptor celi complexes in Crustacea. Microsc. Res. Tech. 22, 325-335.

Hamilton, T. J., Holcombe, A., and Tresguerres, M. (2014). $\mathrm{CO}_{2}$-induced ocean acidification increases anxiety in rockfish via alteration of $\mathrm{GABA}_{\mathrm{A}}$ receptor functioning. Proc. Biol. Sci. U.S.A. 281:20132509. doi: 10.1098/rspb.2013.2509

Hanazato, T. (1991). Pesticides as chemical agents inducing helmet formation in Daphnia ambigua. Limnology 26, 419-424. doi: 10.1111/j.1365-2427.1991.tb01408.x

Hanazato, T., Fueki, K., and Yoshimoto, M. (2001). Fish-induced life-history shifts in the cladocerans Daphnia and Simocephalus: are they positive or negative responses? J. Plankton Res. 23, 945-951. doi: 10.1093/plankt/23.9.945

Harris, K. D. M., Bartlett, N. J., and Lloyd, V. K. (2012). Daphnia as an emerging epigenetic model organism. Genet. Res. Int. 2012:147892. doi: $10.1155 / 2012 / 147892$

Harzsch, S. (2006). Neurophylogeny: architecture of the nervous system and a fresh view on arthropod phyologeny. Integr. Comp. Biol. 46, 162-194. doi: 10.1093/icb/icj011

Harzsch, S., and Glötzner, J. (2002). An immunohistochemical study of structure and development of the nervous system in the brine shrimp Artemia salina Linnaeus, 1758 (Branchiopoda, Anostraca) with remarks on the evolution of the arthropod brain. Arthropod Struct. Dev. 30, 251-270. doi: 10.1016/S1467-8039(02)00012-9

Harzsch, S., and Krieger, J. (2018). Crustacean olfactory systems: a comparative review and a crustacean perspective on olfaction in insects. Prog Neurobiol. 161, 23-60. doi: 10.1016/j.pneurobio.2017.11.005

Hay, M. E. (2009). Marine chemical ecology: chemical signals and cues structure marine populations, communities, and ecosystems. Ann. Rev. Mar. Sci. 1, 193-212. doi: 10.1146/annurev.marine.010908.163708

Hazlett, B. A. (2011). "Chemical cues and reducing the risk of predation," in Chemical Communication in Crustaceans, eds T. Breithaupt and M. Thiel (New York, NY: Springer), 355-370. doi: 10.1007/978-0-387-77101-4_18

Healy, T. M., Bryant, H. J., and Schulte, P. M. (2017). Mitochondrial genotype and phenotypic plasticity of gene expression in response to cold acclimation in killifish. Mol. Ecol. 26, 814-830. doi: 10.1111/mec.13945

Heribert, L. (1915). Untersuchungen über den feineren bau des nervensystems der cladoceren. Arb Zool Inst Univ Wien 20, 297-392.

Herlitze, S., and Landmesser, L. T. (2007). New optical tools for controlling neuronal activity. Curr. Opin. Neurobiol. 17, 87-94. doi: 10.1016/j.conb.2006.12.002

Homberg, U., Christensen, T. A., and Hildebrand, J. G. (1989). Structure and function of the deutocerebrum in insects. Annu. Rev. Entomol. 34, 477-501. doi: 10.1146/annurev.en.34.010189.002401

Isogai, Y., Si, S., Pont-Lezica, L., Tan, T., Kapoor, V., Murthy, V. N., et al. (2011). Molecular organization of vomeronasal chemoreception. Nature 478, 241-245. doi: 10.1038/nature10437 
Jeschke, J. M., Kopp, M., and Tollrian, R. (2002). Predator functional responses: discriminating between handling and digesting prey. Ecol. Monogr. 72, 95-112. doi: 10.1890/0012-9615(2002)072

Kato, Y., Matsuura, T., and Watanabe, H. (2012). Genomic integration and germline transmission of plasmid injected into crustacean Daphnia magna eggs. PLoS ONE 7:e45318. doi: 10.1371/journal.pone.0045318

Kats, L. B., and Dill, L. M. (1998). The scent of death: chemosensory assessment of predation risk by prey animals. Ecoscience 5, 361-394. doi: 10.2307/42902443

Kelly, S. A., Panhuis, T. M., and Stoehr, A. M. (2012). Phenotypic plasticity: molecular mechanisms and adaptive significance. Compr. Physiol. 2, 1417-1439. doi: 10.1002/cphy.c110008

Kirsch, R., and Richter, S. (2007). The nervous system of Leptodora kindtii (Branchiopoda, Cladocera) surveyed with Confocal Scanning Microscopy (CLSM), including general remarks on the branchiopod neuromorphological ground pattern. Arthropod Struct. Dev. 36, 143-156. doi: 10.1016/j.asd.2006.08.013

Kress, T., Harzsch, S., and Dircksen, H. (2016). Neuroanatomy of the optic ganglia and central brain of the water flea Daphnia magna (Crustacea, Cladocera). Cell Tissue Res. 363, 649-677. doi: 10.1007/s00441-015-2279-4

Krueger, D., and Dodson, S. I. (1981). Embryological induction and predation ecology in Daphnia pulex. Limnol. Oceanogr. 26, 219-223. doi: 10.4319/lo.1981.26.2.0219

Kusch, J., and Heckmann, K. (1992). Isolation of theLembadion-factor, a morphogenetically active signal, that induces Euplotes cells to change from their ovoid form into a larger lateral winged morph. Dev. Genet. 13, 241-246. doi: $10.1002 /$ dvg. 1020130311

Lastein, S., Hamdani, E. H., and Døving, K. B. (2015). "Olfactory discrimination of pheromones," in Fish Pheromones and Related Cues, eds P. W. Sorensen and B. D. Wisenden (Wiley Blackwell), 159-195. doi: 10.1002/9781118794739.ch8

Malenka, R. C., and Nicoll, R. A. (1999). Long-term potentiation - a decade of progress? Science 285, 1870-1874. doi: 10.1126/science.285.5435.1870

Meldrum, B. S. (2000). Glutamate as a neurotransmitter in the brain: review of physiology and pathology. J. Nutr. 130(4S Suppl), 1007S-1015S. doi: 10.1093/jn/130.4.1007S

Miner, B. G., Sultan, S. E., Morgan, S. G., Padilla, D. K., and Relyea, R. A. (2005). Ecological consequences of phenotypic plasticity. Trends Ecol. Evol. 20, 685-692. doi: 10.1016/j.tree.2005.08.002

Mitchell, M. D., Bairos-Novak, K. R., and Ferrari, M. C. O. (2017). Mechanisms underlying the control of responses to predator odours in aquatic prey. J. Exp. Biol. 220, 1937-1946. doi: 10.1242/jeb.135137

Miyakawa, H., Sato, M., Colbourne, J. K., and Iguchi, T. (2015). Ionotropic glutamate receptors mediate inducible defense in the water flea Daphnia pulex. PLoS ONE 10:e121324. doi: 10.1371/journal.pone.0121324

Mori, N., and Yoshinaga, N. (2011). Function and evolutionary diversity of fatty acid amino acid conjugates in insects. J. Plant Interact. 6, 103-107. doi: $10.1080 / 17429145.2010 .544412$

Morris, M., and Rogers, S. M. (2014). Ecological Genomics. Dordrecht: Springer. doi: 10.1007/978-94-007-7347-9

Nagayama, S., Homma, R., and Imamura, F. (2014). Neuronal organization of olfactory bulb circuits. Front. Neural Circuits 8:98. doi: $10.3389 /$ fncir. 2014.00098

Naitou, A., Kato, Y., Nakanishi, T., Matsuura, T., and Watanabe, H. (2015). Heterodimeric TALENs induce targeted heritable mutations in the crustacean Daphnia magna. Biol. Open 4, 364-369. doi: 10.1242/bio.20149738

Nakanishi, T., Kato, Y., Matsuura, T., and Watanabe, H. (2014). CRISPR/Casmediated targeted mutagenesis in Daphnia magna. PLoS ONE 9:e98363. doi: 10.1371/journal.pone. 0098363

Nilsson, G. E., Dixson, D. L., Domenici, P., McCormick, M. I., Sørensen, C., Watson, S.-A., et al. (2012). Near-future carbon dioxide levels alter fish behaviour by interfering with neurotransmitter function. Nat. Clim. Chang. 2, 201-204. doi: 10.1038/nclimate1352

Nong, Q. D., Mohamad Ishak, N. S., Matsuura, T., Kato, Y., and Watanabe, H. (2017). Mapping the expression of the sex determining factor Doublesex1 in Daphnia magna using a knock-in reporter. Sci. Rep. 7:13521. doi: 10.1038/s41598-017-13730-4

Peacor, S. D. (2003). Phenotypic modifications to conspecific density arising from predation risk assessment. Oikos 100, 409-415. doi: $10.1034 / j .1600-0706.2003 .12043 . x$
Peñalva-Arana, D. C., Lynch, M., and Robertson, H. M. (2009). The chemoreceptor genes of the waterflea Daphnia pulex: many Grs but no Ors. BMC Evol. Biol. 9:79. doi: $10.1186 / 1471-2148-9-79$

Pereira, A. G., and Moita, M. A. (2016). Is there anybody out there? Neural circuits of threat detection in vertebrates. Curr. Opin. Neurobiol. 41, 179-187. doi: 10.1016/j.conb.2016.09.011

Petrusek, A., Tollrian, R., Schwenk, K., Haas, A., and Laforsch, C. (2009). A "crown of thorns" is an inducible defense that protects Daphnia against an ancient predator. Proc. Natl. Acad. Sci. U.S.A. 106, 2248-2252. doi: 10.1073/pnas.0808075106

Picciotto, M. R., Higley, M. J., and Mineur, Y. S. (2012). Acetylcholine as a neuromodulator: cholinergic signaling shapes nervous system function and behavior. Neuron 76, 116-129. doi: 10.1016/j.neuron.2012.08.036

Pohnert, G., Steinke, M., and Tollrian, R. (2007). Chemical cues, defence metabolites and the shaping of pelagic interspecific interactions. Trends Ecol. Evol. 22, 198-204. doi: 10.1016/j.tree.2007.01.005

Poulin, R. X., Lavoie, S., Siegel, K., Gaul, D. A., Weissburg, M. J., and Kubanek, J. (2018). Chemical encoding of risk perception and predator detection among estuarine invertebrates. Proc. Natl. Acad. Sci. U.S.A. 115, 662-667. doi: 10.1073/pnas.1713901115

Reger, J., Lind, M. I., Robinson, M. R., and Beckerman, A. P. (2018). Predation drives local adaptation of phenotypic plasticity. Nat. Ecol. Evol. 2, 100-107. doi: 10.1038/s41559-017-0373-6

Ringelberg, J. (2010). Diel Vertical Migration of Zooplankton in Lakes and Oceans. Dordrecht: Springer. doi: 10.1007/978-90-481-3093-1

Rivetti, C., Campos, B., Piña, B., Raldúa, D., Kato, Y., Watanabe, H., et al. (2018). Tryptophan hydroxylase (TRH) loss of function mutations induce growth and behavioral defects in Daphnia magna. Sci. Rep. 8:1518. doi: 10.1038/s41598-018-19778-0

Robichaud, N. F., Sassine, J., Beaton, M. J., and Lloyd, V. K. (2012). The epigenetic repertoire of Daphnia magna includes modified histones. Genet. Res. Int. 2012:174860. doi: $10.1155 / 2012 / 174860$

Rozenberg, A., Leese, F., Weiss, L. C., and Tollrian, R. (2016). Digital gene expression analysis with sample multiplexing and PCR duplicate detection: a straightforward protocol. BioTechniques 61, 26-32. doi: 10.2144/000114434

Rozenberg, A., Parida, M., Leese, F., Weiss, L. C., Tollrian, R., and Manak, J. R. (2015). Transcriptional profiling of predator-induced phenotypic plasticity in Daphnia pulex. Front. Zool. 12:18. doi: 10.1186/s12983-015-0109-x

Ruther, J., Meiners, T., and Steidle, J. L. M. (2002). Rich in phenomenalacking in terms. A classification of kairomones. Chemoecology 12, 161-167. doi: $10.1007 /$ PL00012664

Samuk, K., Xue, J., and Rennision, D. J. (2018). Exposure to predators does not lead to the evolution of larger brains in experimental populations of threespine stickleback. Evolution 72, 916-929. doi: 10.1111/evo.13444

Schwarzenberger, A., Courts, C., and von Elert, E. (2009). Target gene approaches: gene expression in Daphnia magna exposed to predator-borne kairomones or to microcystin-producing and microcystin-free Microcystis aeruginosa. BMC Genomics 10:527. doi: 10.1186/1471-2164-10-527

Selander, E., Kubanek, J., Hamberg, M., Andersson, M. X., Cervin, G., and Pavia, H. (2015). Predator lipids induce paralytic shellfish toxins in bloom-forming algae. Proc. Natl. Acad. Sci. U.S.A. 112, 6395-6400. doi: 10.1073/pnas.1420154112

Simbeya, C. K., Csuzdi, C. E., Dew, W. A., and Pyle, G. G. (2012). Electroantennogram measurement of the olfactory response of Daphnia spp. and its impairment by waterborne copper. Ecotoxicol. Environ. Saf. 82, 80-84. doi: 10.1016/j.ecoenv.2012.05.011

Simon, J. C., Pfrender, M. E., Tollrian, R., Tagu, D., and Colbourne, J. K. (2011). Genomics of environmentally induced phenotypes in 2 extremely plastic arthropods. J. Heredity 102, 512-525. doi: 10.1093/jhered/esr020

Sorensen, P. W., and Stacey, N. E. (2004). Brief review of fish pheromones and discussion of their possible uses in the control of nonindigenous teleost fishes. New Zeal. J. Mar. Freshw. Res. 38, 399-417. doi: 10.1080/00288330.2004.9517248

Spanier, K. I., Leese, F., Mayer, C., Colbourne, J. K., Gilbert, D., Pfrender, M. E., et al. (2010). Predator-induced defences in Daphnia pulex: selection and evaluation of internal reference genes for gene expression studies with real-time PCR. BMC Mol. Biol. 11:50. doi: 10.1186/1471-2199-11-50

Spoida, K., Masseck, O. A., Deneris, E. S., and Herlitze, S. (2014). Gq/5-HT2c receptor signals activate a local GABAergic inhibitory feedback circuit to 
modulate serotonergic firing and anxiety in mice. Proc. Natl. Acad. Sci. U.S.A. 111, 6479-6484. doi: 10.1073/pnas.1321576111

Stollewerk, A. (2010). The water flea Daphnia - a "new" model system for ecology and evolution? J. Biol. 9:221. doi: 10.1186/jbiol212

Strausfeld, N., and Reisenman, C. E. (2009). Dimorphic olfactory lobes in the arthropoda. Ann. N. Y. Acad. Sci. 1170, 487-496. doi: 10.1111/j.1749-6632.2009.04020.x

Theißen, G., and Melzer, R. (2016). Robust views on plasticity and biodiversity. Ann. Bot. 117, 693-697. doi: 10.1093/aob/mcw066

Tollrian, R. (1990). Predator induced helmet formation in Daphnia cucullata (SARS). Arch. Hydrobiol. 2, 191-196.

Tollrian, R. (1993). Neckteeth formation in Daphnia pulex as an example of continuous phenotypic plasticity morphological effects of Chaoborus kairomone concentration and their quantification. J. Plankton Res. 15, 1309-1318.

Tollrian, R. (1994). Fish-kairomone induced morphological changes in Daphnia lumholtzi (Sars). Arch. Hydrobiol.130, 69-75.

Tollrian, R. (1995). Predator-induced morphological defenses: costs, life history shifts, and maternal effects in Daphnia pulex. Ecology 76, 1691-1705. doi: $10.2307 / 1940703$

Tollrian, R., Duggen, S., Weiss, L. C., Laforsch, C., and Kopp, M. (2015). Density-dependent adjustment of inducible defenses. Sci. Rep. 5:12736. doi: $10.1038 /$ srep 12736

Tollrian, R., and Harvell, C. D. (1999). The Ecology and Evolution of Inducible Defenses. Princeton University Press.

Tollrian, R., and Leese, F. (2010). Ecological genomics: steps towards unraveling the genetic basis of inducible defenses in Daphnia. BMC Biol. 8:51. doi: 10.1186/1741-7007-8-51

Troyer, R. R., and Turner, A. M. (2015). Chemosensory perception of predators by larval amphibians depends on water quality. PLoS ONE 10:e131516. doi: 10.1371/journal.pone.0131516

Verschoor, A. M., Vos, M., and Van Der Stap, I. (2004). Inducible defences prevent strong population fluctuations in bi- and tritrophic food chains. Ecol. Lett. 7, 1143-1148. doi: 10.1111/j.1461-0248.2004.00675.x

Vos, M., Kooi, B. W., De Angelis, D. L., and Mooij, W. M. (2006). "Inducible defenses in food webs," in Dynamic Food Webs, eds P. de Ruiter, V. Wolters, J. C. Moore, and K. Melville-Smith (Elsevier), 114-127. doi: 10.1016/B978-012088458-2/50013-8

Vosshall, L. B., Amrein, H., Morozov, P. S., Rzhetsky, A., and Axel, R. (1999). A spatial map of olfactory receptor expression in the Drosophila antenna. Cell 96, 725-736. doi: 10.1016/S0092-8674(00)80582-6

Weiss, L. C., Heilgenberg, E., Deussen, L., Becker, S. M., Kruppert, S., and Tollrian, R. (2016). Onset of kairomone sensitivity and the development of inducible morphological defenses in Daphnia pulex. Hydrobiologia 779, 135-145. doi: 10.1007/s10750-016-2809-4

Weiss, L. C., Kruppert, S., Laforsch, C., and Tollrian, R. (2012a). Chaoborus and Gasterosteus anti-predator responses in Daphnia pulex are mediated by independent cholinergic and gabaergic neuronal signals. PLoS ONE 7:e36879. doi: 10.1371/journal.pone.0036879

Weiss, L. C., Laforsch, C., and Tollrian, R. (2012b). The taste of predation and the defences of prey. Chem. Ecol. Aquat. Syst. 1, 111-126. doi: 10.1093/acprof:osobl/9780199583096.003.0009

Weiss, L. C., Leimann, J., and Tollrian, R. (2015). Predator-induced defences in Daphnia longicephala: location of kairomone receptors and timeline of sensitive phases to trait formation. J. Exp. Biol. 218, 2918-2926. doi: 10.1242/jeb. 124552

Weiss, L. C., Pötter, L., Steiger, A., Kruppert, S., Frost, U., and Tollrian, R. (2018). Rising $\mathrm{pCO}_{2}$ in freshwater ecosystems has the potential to negatively affect predator-induced defenses in Daphnia. Curr. Biol. 28, 327-332.e3. doi: 10.1016/j.cub.2017.12.022

Weiss, L. C., and Tollrian, R. (2018). "Predator induced defenses in Crustacea," in The Natural History of Crustacea: Life Histories, Vol. 5 (New York, NY: Oxford University Press).

Weiss, L. C., Tollrian, R., Herbert, Z., and Laforsch, C. (2012c). Morphology of the daphnia nervous system: a comparative study on Daphnia pulex, Daphnia lumholtzi, and Daphnia longicephala. J. Morphol. 273, 1392-1405. doi: 10.1002/jmor.20068

West-Eberhard, M. J. (2005). Developmental plasticity and the origin of species differences. Proc. Natl. Acad. Sci. U.S.A. 102(Suppl.), 6543-6549. doi: $10.1073 /$ pnas. 0501844102

Wicher, D. (2018). Tuning insect odorant receptors. Front. Cell. Neurosci. 12:94. doi: $10.3389 /$ fncel.2018.00094

Wisenden, B. D. (2000). Olfactory assessment of predation risk in the aquatic environment. Philos. Trans. R. Soc. B Biol. Sci. 355, 1205-1208. doi: $10.1098 /$ rstb. 2000.0668

Wisenden, B. D. (2015). "Chemical cues that indicate risk of predation," in Fish Pheromones and Related Cues, eds P. W. Sorensen and B. D. Wisenden (Hoboken, NJ: John Wiley \& Sons, Inc.), 131-148.

Wright, M. L., Jorey, S. T., Myers, Y. M., Fieldstad, M. L., Paquette, C. M., and Clark, M. B. (1988). Influence of photoperiod, daylength, and feeding schedule on tadpole growth and development. Dev. Growth Differ. 30, 315-323. doi: 10.1111/j.1440-169X.1988.00315.x

$\mathrm{Wu}$, C., and Sun, D. (2015). GABA receptors in brain development, function, and injury. Metab. Brain Dis. 30, 367-379. doi: 10.1007/s11011-014-9 560-1.GABA

Yasumoto, K., Nishigami, A., Yasumoto, M., Kasai, F., Okada, Y., Kusumi, T., et al. (2005). Aliphatic sulfates released from Daphnia induce morphological defense of phytoplankton: isolation and synthesis of kairomones. Tetrahedron Lett. 46, 4765-4767. doi: 10.1016/j.tetlet.2005. 05.027

Ye, Z., Xu, S., Spitze, K., Asselman, J., Jiang, X., Ackerman, M. S., et al. (2017). A new reference genome assembly for the microcrustacean Daphnia pulex. G3 7, 1405-1416. doi: 10.1534/g3.116.038638

Yoshinaga, N. (2016). Physiological function and ecological aspects of fatty acid-amino acid conjugates in insects. Biosci. Biotechnol. Biochem. 80, 1274-1282. doi: 10.1080/09168451.2016.11 53956

Conflict of Interest Statement: The author declares that the research was conducted in the absence of any commercial or financial relationships that could be construed as a potential conflict of interest.

Copyright (c) 2019 Weiss. This is an open-access article distributed under the terms of the Creative Commons Attribution License (CC BY). The use, distribution or reproduction in other forums is permitted, provided the original author(s) and the copyright owner(s) are credited and that the original publication in this journal is cited, in accordance with accepted academic practice. No use, distribution or reproduction is permitted which does not comply with these terms. 